\title{
Landscape-town-planning reconstruction of the spatially-planning structure of destroyed cities (On the example of the cities of Baghdad and Mosul)
}

\author{
Layij Jasim Sumayah, ${ }^{1, *}$ \\ ${ }^{1}$ Volgograd State Technical University, Volgograd, Russia
}

\begin{abstract}
The problem of restoring the spatial planning structure of the major cities of Iraq - Baghdad and Mosul, destroyed during the war of 2003-2011. Is currently relevant for ensuring their sustainable development and the formation of a comfortable, safe and environmentally-oriented urban environment. The study of the dynamics of the transformation of urban fabric of Baghdad and Mosul has a number of historical and methodological features related to specific socio-economic, cultural, historical and landscape-urban conditions that ensure their sustainable development in the future. An analysis of the dynamics of changes in the urban fabric of Baghdad and Mosul, which occurred as a result of military operations in these cities, made it possible to determine the priority areas of urban development, which in the future will ensure the formation of sustainable spatial planning structures of these cities. Proceeding from landscape, ecological and historical-architectural and urban development features of the cities of Baghdad and Mosul, the priority direction is landscape-urban reconstruction, based on the principles of landscape urbanism, which will restore and make accessible to residents and visitors of the city the lost historical and architectural objects, preserve identity historical and cultural environment through integration with the transport and green framework, linking the functional and planning zones of the city in a single "infrastructur" At present, such a strategy of urban transformation is used in the restoration of the historical cities of Iraq Baghdad and Mosul.
\end{abstract}

\section{Introduction}

The history knows a large number of cases when the injured or completely destroyed by the fighting actions of the city received a new life and a new layout. Such cities are also present in the countries of the former USSR. A striking example is Volgograd, whose center was destroyed by the enemy during the Second World War. As well as the city of Mosul after its liberation from the organization of the Islamic state in Iraq and Syria (ISIS).

\footnotetext{
* Corresponding author: sumaya arch@yahoo.com
} 


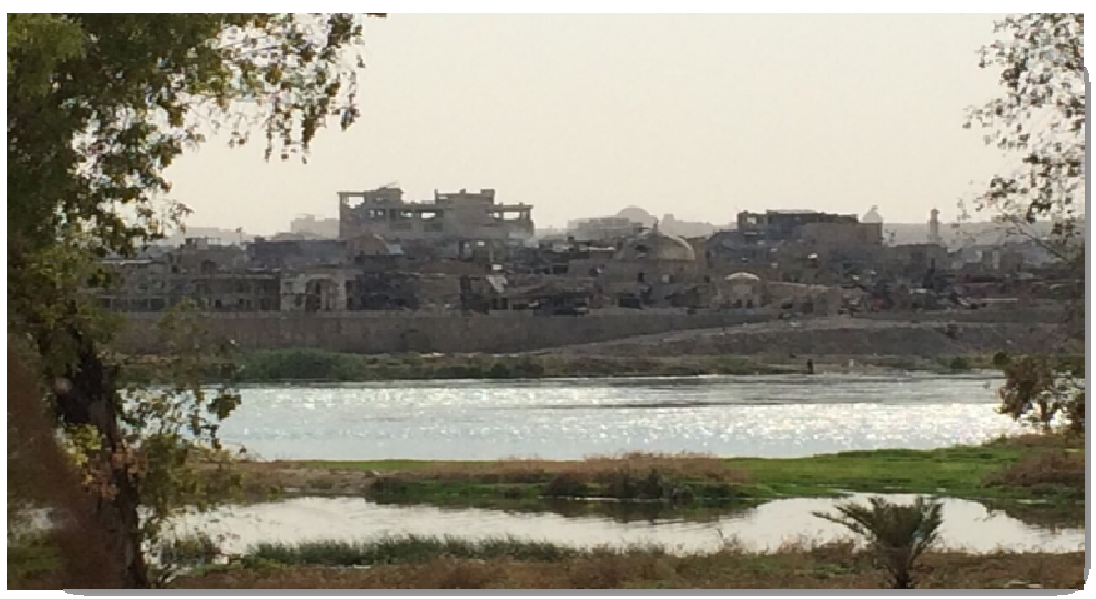

Fig. 1. The city of Mosul after its liberation from the organization (ISIS)._Source: Researcher.

In this paper, we will talk about the basic principles of reconstruction of survivors of hostilities. The main examples in the work will be Baghdad ( 8.5 million people live) and Mosul ( 2 and a half million people live). These cities suffered significant losses and destruction during military operations in Iraq since 2003. This territory contains a significant number of ancient monuments of civilization. The legendary city of Babylon and the valleys of the Tigris and Euphrates rivers are located here. Baghdad itself has more than 1200 years of history. To date, Baghdad is the official and actual capital of Iraq. The city of Mosul has a much earlier history. According to the excavations, people live on its territory for more than 8000 years, and the foundation of the city itself is dated to the 7 th century BC. e. [1]. If today Baghdad implements a number of town-planning projects for the organization of new territories and the restoration of the destroyed parts of the city after the fighting, the city of Mosul for three years was in occupation by the terrorist organization "Islamic State" and is now in decline.

\section{An analysis of the dynamics of the transformation of urban fabric of Baghdad and Mosul}

An analysis of the dynamics of the transformation of urban fabric of Baghdad and Mosul has a number of historical and methodological features related to specific socio-economic, cultural, historical and landscape-urban conditions that ensure their sustainable development in the future.

The military operations in Iraq and Baghdad took place in 2003. This plan demonstrates the city's historic road network and its transport infrastructure. In Fig. 2 shows the plan of the city, which reflects the current state of the planning structure of the city and demonstrates that in the city after the hostilities the former structure of the street-road network has been preserved.

Thus, it can be concluded that the historically developed geometry of the city plan is preserved, which ensures the stability of its spatial planning structure and is an important factor for the restoration of the destroyed city, which has in its structure objects of history, architecture and culture of world significance. 

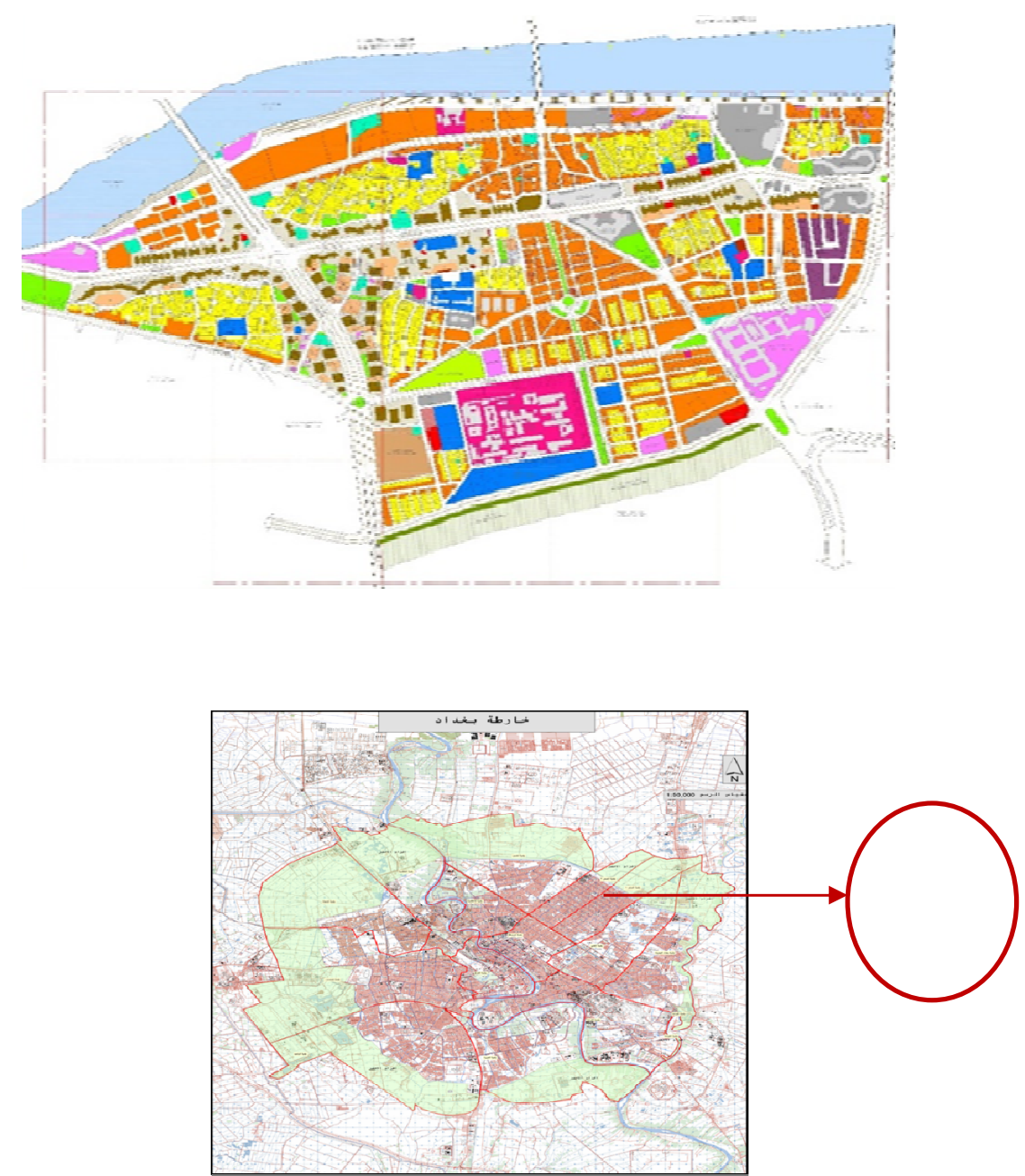

Fig. 2. CoC. The modern plan of the center of Baghdad.

The city of Mosul today is within the largest of all modern military conflicts, in the elimination of which more than 60 countries of the world take part. The city suffers regular bombardments, a significant part of the city is destroyed. Therefore, the city of Mosul still has to be restored in the future, but only after a complete cessation of the military conflict in the Middle East.

\section{Principles for the restoration of cities}

Considering the problem of rehabilitation and rehabilitation of cities that have suffered as a result of hostilities, it is necessary to be guided by certain principles of carrying out these activities. It:

1-The principle of centrality carrying out of measures for the primary restoration of the city center. Particular attention should be paid to the restoration of the historical center, since the restoration of the structure of the historical center directly affects the further development of the planning structure of the city as a whole. Recreating the proportions of the historical center is associated with the construction of the city's major urban ensembles. Preservation of the "genetic code of the city center" has an important social and town- 
planning significance, since the "memory of the place" is passed on to the next generations and ensures sustainable development of the city.

2-Principle of priority in the restoration of urban ensembles Historical ensembles that are being restored must become part of the city's organism and not be isolated islands of history in the city.

3-The principle of reproduction of the lost historical environment. This means the most accurate reproduction of the historical environment

The most accurate reproduction of the historical environment necessary to preserve the spatial planning of the city .

4-The principle of "impregnations"Perhaps the use of "interspersions," namely, the introduction of a new architecture in historical urban context, recreated about historical archival documents, to maintain the historical appearance of the city. Creation of architectural "impregnations" that do not imitate the old styles and prototypes. This approach ensures the preservation of the basic elements of the spatial planning structure, in order not to contrast with the surrounding architectural environment.

5-The principle of recreating the lost architectural panorama of the city Reconstruction and reconstruction of the architectural appearance of the facades of historic buildings, preserving the basic parameters and principles of composing the formation of architectural panoramas of streets, squares and embankments in this city.

6-The principle of creating a "blue-green infrastructure of the city" on the basis of the formation of a green framework of the city. Creation of a continuous system of city greening, based on maximum permeability of natural components of the entire spatial planning structure, in conjunction with the river and other natural or artificially created water areas (ponds, canals, basins, etc.) and fountains, cascades, etc. This will ensure the creation of favorable environmental conditions for the population.

7- The principle of the scenario approach to the creation of a system of public spaces. The creation of a social scenario of the system of public spaces is aimed at the formation of a socially-oriented and safe environment of the public spaces of the restored cities.

\section{The importance of landscape-town-planning reconstruction of the spatially-planning structure of destroyed cities in the context of sustainable development}

If we focus on the landscape and town-planning context of urban reconstruction, it is necessary to develop conceptual proposals for the formation of a master plan of the city in conjunction with the formation of the green framework of the city - its green infrastructure in accordance with modern principles of landscape urbanism [5: 120,124,]. And also the creation of hybrid quarters, a large number of green spaces, the privileges of public transport over private ones.

It is necessary to take into account the rather droughty climatic conditions of the cities under consideration. Therefore, the creation of a green infrastructure of the city is a priority of its urban development. Baghdad is located almost in the center of Iraq, on the banks of the Tigris River, not far from the mouth of the Diyala River. Weather conditions in the city and its surroundings are formed under the influence of the subtropical and Mediterranean climate.

Given these characteristics, it is worthwhile to organize in the city a multi-level system of green plantations using evergreen varieties and with a great possibility of shading. In the city, it is necessary to minimize the amount of asphalt and concrete surfaces, as they are capable of artificially raising the temperature of the surrounding air. 


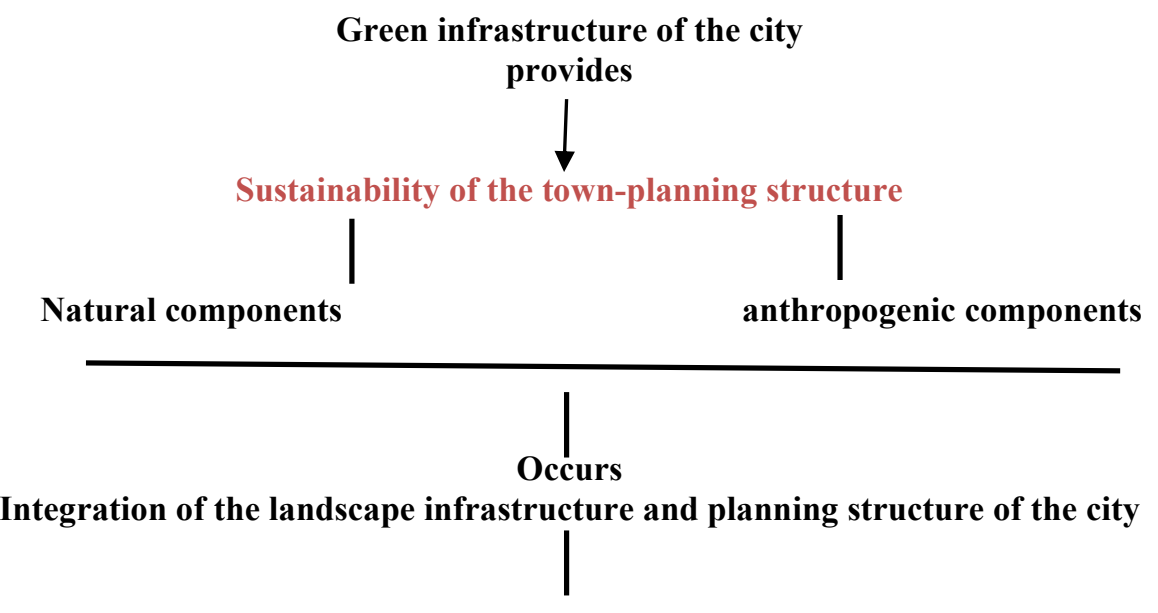

Theory and practice of landscape urbanism

Fig.3. The effect of the city's green infrastructure on the sustainable development of the city in the context of landscape urbanism. (C) EE Krasilnikova

Requires the new city in Iraq is built on the basis of a socially-oriented approach and with properly defined priorities for its further urban development. At the same time, the architectural component of the project is worked out at all, and the houses were built using high-quality technology, to form a sustainable spatial and planning structure of the city. The city of Mosul is in a much more deplorable state and position compared to Baghdad. In 2017, fighting took place on its territory between the "Islamic state" and the Iraqi authorities. This is the second largest city in the country, during the occupation it lost more than 700 thousand people who left this city. Today, Mosul is in roughly the same position as Baghdad after the cessation of hostilities in Iraq. In this city today, the solution of all social problems is necessary, after which it is necessary to start its restoration. [4] It should be noted that the city has preserved a large number of architectural monuments, which need to be restored and equipped along with the recreational zones adjacent to them. It is possible to build temporary housing in other places, outside the city at the time of its restoration. Therefore, when designing new quarters or reconstructing and restoring existing buildings, it is necessary to preserve and restore the old street-road network of cities, take into account the areas of preserved historical, architectural and cultural monuments, support the social sphere and create conditions for comfortable living of residents. Nevertheless, the main condition for the further restoration of cities will always be the desire to end hostilities and maintain peaceful and friendly relations in these territories.

\section{Principles of landscape-urban reconstruction}

Baghdad is one of the most famous cultural and historical centers not only of the Middle East, but of the whole world. Middle Eastern culture was emerging on the territory of modern Iraq. Therefore, the main task of urban planners was to restore the historical appearance of Baghdad after the hostilities. The main principles underlying the measures to restore the city are:

1. The principle of contextual integration. Preservation of the historical territories of the city and the integration of natural components in them. Preservation of certain objects or 
ruins, which destroys the city structure, since this is inadmissible and contradicts the basic principles of restoration listed in this paper.

2. The principle of environmental optimization. Restoring vitality and creating a comfortable environment of the city by reconstructing the street-road network in accordance with the historically established structure (in its former form) in the central historical part of the city in conjunction with the "blue-green infrastructure of the city". Introduction of modern technologies in the formation of a socially-oriented transport infrastructure of the city and communicative spaces that are in symbiosis with the environment, with a historical part of the proud bearing the cultural traditions of the previous historical development. [5: 119]

3. The principle of stylistic similarity. Restoration of historical monuments using the same or similar materials that would meet the period of their creation, preserving the color and architectural image of these objects of the natural environment, heritage and protection.

4. Principle of biopositivity. This is the maximum inclusion of natural components in the structure of the city and a careful attitude to the existing natural resources. The principle of biopositivity is the basis for increasing the role of the natural framework in the filling of specially protected spaces and consists in the primary choice of components of nature for the purposes of eco-reconstruction and design of natural parks. A significant role is also given to the regeneration of existing landscapes in the city structure. The introduction of natural components into mass housing construction, which will enable the creation of a competitive, environmentally oriented housing and form a stable and comfortable living environment. Creation of hybrid residential quarters, which will contribute to the formation of a unique and memorable look. [6]

\section{Conclusions}

The negative side of civilization is that virtually at any point in time in certain parts of the globe, military actions and military conflicts occur, as a result of which civilians and cities suffer. Therefore, a very important scientific and practical aspect in the theory and practice of urban development is the restoration of urban settlements after hostilities, which should be guided by a number of principles aimed at creating a new quality urban environment while preserving the historical heritage that is in the given territory. Each city has its own specificity, conditioned by various factors - the peculiarities of historical development, the formation of a spatial-structure structure, the socio-economic context, etc. Therefore, the principles of landscape-urban reconstruction should be developed specifically for a particular city. Landscape and urban reconstruction is a modern method of restoring the city in order to create a comfortable socially-oriented and environmentally safe and stable environment.

\section{References}

1. P.V. Gusterin, Cities of the Arab East. East-West, p. 352, Encyclopedic reference book, ISBN 978-5-478-00729-4 (2007)

2. http://russian.korea.net/NewsFocus/ Business / view? ArticleId = 143024;

3. Encyclopedia of the Modern Middle East and North Africa (2004)

4. https://www.bbc.com/russian/features-40890876

5. E.E. Krasilnikova, Landscape Urbanism. Theory-Practice: Part.1. (LTD "IAA" District news, Volgograd (2015) 
6. E.E. Krasilnikova, V.A. Rusanov, L.A. Kuzina, Bulletin of the Volgograd State University of Architecture and Civil Engineering, series: building and architecture, 36 (55), pp.275-283 (2014) 